\title{
La construcción de la voz del enunciador en el discurso politico de Ricardo Lagos, ex Presidente de la República
}

ANA MARÍA BURDACH R.

PAULA ROSS A.

Pontificia Universidad Católica de Chile

Resumen. Esta investigación parte del supuesto de que en el enunciador del discurso presidencial de inauguración del año legislativo de la nación chilena, el ex Presidente de la República de Chile, Ricardo Lagos Escobar, se pueden identificar tres voces enunciativas. En el trabajo se identifican y describen dichas voces manifestadas mediante determinados marcadores formales de carácter pragmático, se establece la correlación de estas con la fuerza ilocutiva de los actos de habla y con algunas de las funciones pragmáticas que contribuyen a la construcción de las mismas. Los resultados revelan el empleo de marcadores que construyen voces mayoritariamente colectivas que consolidan al ex líder de gobierno como parte de un amplio conglomerado. La metodología empleada es tanto cuantitativa como cualitativa. La investigación se basa en datos obtenidos del análisis de un corpus de habla pública recopilado como parte del proyecto de investigación Fondecyt No 1030953, realizado en la Pontificia Universidad Católica de Chile.

Palabras clave: discurso presidencial, voz del enunciador, fuerza ilocutiva, funciones pragmáticas

Resumo. Esta pesquisa parte do suposto de que no enunciador do discurso presidencial de inauguração do ano legislativo da nação chilena, o exPresidente da República de Chile, Ricardo Lagos Escobar, pode-se identificar três vozes enunciativas. No trabalho identificam-se e descreve-se tais vozes manifestadas mediante determinados marcadores formais de caráter pragmático, estabelece-se a correlação destas com a força ilocutiva dos atos de fala e com algumas das funções pragmáticas que contribuem à construção das mesmas. Os resultados revelam o emprego de marcadores que constroem vozes majoritariamente coletivas que consolidam ao exlíder de governo como parte de um amplo conglomerado. A metodologia empregada é tanto quantitativa quanto qualitativa. A pesquisa se baseia em dados obtidos da análise de um corpus de fala pública recompilado como parte do projeto de pesquisa Fondecyt No 1030953, realizado na Pontifícia Universidade Católica de Chile.

Palavras chave: discurso presidencial, voz do enunciador, força ilocutiva, funçōes pragmáticas 
Abstract. This research hypothesizes that there are three identifiable voices in the voice of the enunciator, the ex President of the Republic of Chile Ricardo Lagos Escobar, in the Inaugural Presidential Speech of the Chilean Legislative year. This paper presents the identification and description of the three voices signalled at the level of discourse by specific formal pragmatic markers, establishes a correlation between the identified voices, the illocutionary force of the speech acts and some of the pragmatic functions that help to construct the voice of the enunciator. The results reveal the presence of markers that construct voices that are mainly collective which consolidate the ex government leader as part of a wider group. The methodology designed to carry out the research is quantitative as well as qualitative. The research bases itself on data obtained from the analysis of public speech corpora, collected as part of the Fondecyt project No 1030953, carried out at the Pontificia Universidad Católica de Chile.

Key words: presidential speech; voice of the speaker; illocutionary force; pragmatic functions

\section{Introducción}

En este artículo presentamos un estudio sobre las diferentes voces enunciativas y su integración en el discurso presidencial del 21 de mayo del ex Presidente de la República de Chile, Ricardo Lagos Escobar, al inicio de la legislatura ordinaria del año 2003, en el que rinde cuentas al país y al Congreso sobre la situación general de la nación.

Este trabajo aborda el problema de verificar si la identificación y descripción de los recursos lingüísticos y pragmáticos permiten establecer las visiones del YO y de los otros como una estrategia en este discurso. Es por ello que esta investigación parte del supuesto de que en la voz del enunciador se pueden identificar tres tipos de voces, las que se manifiestan a través de determinados marcadores formales que se relacionan con la fuerza ilocutiva de los actos de habla emitidos por éste, a la vez que con algunos recursos de focalización que le dan mayor expresividad al contenido del discurso presidencial.

Creemos que la correlación entre los marcadores formales de estas voces y los actos de habla empleados en el discurso, contribuirá a dejar de manifiesto la forma en que un estadista carismático y de gran popularidad como Ricardo Lagos, ex Presidente de la República de Chile ${ }^{2}$, construye su identidad en un momento histórico en que existe evidencia del progreso y modernización de la nación en los ámbitos de educación, vivienda, justicia, salud, agricultura, infraestructura vial y cultura; que ofrece una mejor calidad de vida a sus ciudadanos-dignidad y libertad, erradicación de la pobreza y freno al desempleo-; que a nivel internacional gana prestigio con la firma de tratados de Libre Comercio y que 
asume una actitud responsable frente a la guerra de Irak en el seno del Consejo de Seguridad de Naciones Unidas.

La investigación, de carácter descriptivo, se basa en datos obtenidos del análisis de un corpus de habla pública, recopilado como parte del proyecto de investigación Fondecyt No $1030953^{3}$ realizado en la Pontificia Universidad Católica de Chile.

\section{Antecedentes teóricos}

El discurso político corresponde a una forma de acción política y a un componente del proceso político que revela el poder y la autoridad de quien lo emite (van Dijk, 1995; Molero, 2002). Se trata de un género discursivo, de carácter monolocutivo, constituido por secuencias con inicio, desarrollo y término, con su propia apertura y cierre (Burdach y Samaniego, 2005). Dentro del marco de una situación pragmática definida, el enunciador construye su discurso en función de su identidad como protagonista de una situación comunicativa espacio-temporal específica, hace uso de su competencia construccional a partir del aparato formal de la lengua y de las reglas combinatorias de éste en conformidad con el marco situacional, con los propósitos del discurso, con las exigencias de organización del mismo y con las circunstancias materiales de producción (Charaudeau, 2001).

Si bien este género discursivo pareciera tener un carácter monológico, corresponde a un intercambio entre hablantes en el que el enunciador se orienta hacia un destinatario, expresa su relación con el 'otro' y construye su propia imagen desde el punto de vista de él o los destinatarios. En efecto, la presencia fundamental de un 'yo' enunciador y de un 'tu' (pro, para y contradestinatario) evidencian el carácter dialógico de esta práctica discursiva. De hecho, en el momento en que el enunciador se declara locutor, implanta al otro ante sí mismo constituyéndose ambos en coprotagonistas de la interacción comunicativa (Goffman, 1959, 1967, 1971, 1981)

En el 'discurso presidencial', el enunciador se adueña del espacio de tematización, lo introduce, lo impone al otro, lo desarrolla a conveniencia, construye su propio Yo en función de la imagen que de sí mismo desea transmitir, anticipa e imagina las reacciones de un Tú, real o virtual, modaliza su discurso, denomina y evalúa el mundo, describe acciones, organiza su argumento y enfatiza lo que estima relevante para los propósitos de su intervención (Charaudeau, 2001). Todo ello a través de la cuidadosa selección de actos de habla y sus respectivos exponentes verbales que expresan la fuerza ilocutiva empleada por el enunciador ${ }^{4}$. 
Desde el punto de vista de las funciones pragmáticas, el enunciador ordena la información de acuerdo a los requerimientos de la situación; contrasta y focaliza cierta información por sobre otra destacando aquello que le interesa que los ciudadanos conozcan o recuerden en relación con su mandato'.

Por ello, al construir su discurso como protagonista de una situación comunicativa, el enunciador puede emplear una diversidad de voces (Ducrot, 1984) explicitadas en el discurso a través de distintos marcadores para configurar su forma de autopresentación y su relación con los demás. Es por ello que nos planteamos el problema de si la identificación y descripción de los recursos lingüísticos y pragmáticos permiten establecer las visiones del YO y de los otros como una estrategia en este discurso.

\section{Metodología y corpus}

El corpus de nuestra investigación constituye parte de un corpus mayor de habla pública que reúne muestras pertenecientes a emisiones que se producen en distintos ámbitos de la actividad social nacional: académico/cultural, castrense, cívico/político, empresarial, gremial/sindical, mediático y religioso. Para los fines de este trabajo, hemos seleccionado del ámbito cívico/político, la totalidad del discurso presidencial de Ricardo Lagos emitido el 21 de mayo de 2003.

Para la metodología de trabajo, consideramos los siguientes pasos:

1. Transliteración del discurso presidencial.

2. Clasificación de los actos de habla según la taxonomía de Searle (1969), complementada con la subcategorización propuesta por Moreno Cabrera (1994).

3. Identificación de los marcadores formales (deícticos y desinencias verbales) que plasman en el discurso los tres tipos de voces enunciativas.

4. Clasificación y cuantificación de los marcadores formales en relación con el tipo de voz.

5. Correlación entre los tipos actos de habla y los marcadores formales correspondientes.

6. Identificación de algunos recursos de focalización asociados a los marcadores formales que se materializan en los tipos de voces enunciativas.

7. Correlación entre actos de habla, voces enunciativas y recursos de focalización que las materializan. 


\section{Las voces en el discurso}

El estudio en contexto de los marcadores formales (deícticos y desinencias verbales) revela la presencia de tres voces con alta frecuencia de ocurrencia, sin por ello descartar la presencia de otras:

- la voz del Presidente de la República o Jefe de Estado,

- la voz del Presidente como parte de un gobierno y

- la voz del Presidente como parte de la nación.

Ahora bien, si consideramos que el protagonista del género en estudio es el Presidente de la República, vale decir, un participante único, se podría partir del supuesto de que en esta práctica discursiva el empleo de marcadores formales de primera persona del singular se vería favorecido a través de una continua autorreferencia. Sin embargo, los resultados revelan que la suma de los marcadores de primera persona singular o grupo 'yo' es significativamente menor a aquella obtenida por los marcadores de primera persona plural o grupo 'nosotros' que incorporan al enunciador dentro de un colectivo (57 versus 284). El estudio e interpretación de estos marcadores se realiza en los siguientes apartados.

\subsection{MARCADORES FORMALES DEL GRUPO ' $Y O$ '}

El estudio de los marcadores formales del grupo ' $y o$ ', materializados a través del deíctico ' $y o$ ', con sus respectivas desinencias verbales, además del pronombre ' $m e$ ' y el adjetivo posesivo ' $m i$ ', revela que el enunciador emplea la primera persona del singular - 'yo'- para canalizar la $V o z 1$ o la voz del Presidente de la República o Jefe de Estado. La presencia de este marcador en el discurso evidencia un deseo de posicionarse en grados de mayor o menor cercanía con el destinatario y, por ende, implica una dimensión personal o afectiva; vale decir, el uso de los marcadores del grupo 'yo' denota un movimiento entre el Presidente/persona y el Presidente/jefe de estado en grados de mayor o menor cercanía con el destinatario. A través de la selección de este 'yo' público, el Presidente se responsabiliza del contenido de lo dicho, se impone a los demás y/o se muestra en su dimensión humana: el Presidente/persona que agradece, felicita y aconseja:

Yo quiero agradecer particularmente el esfuerzo de la Cámara de Diputados, que permitió que de los cinco proyectos que se enviaron, cuatro se despacharan durante el segundo semestre de dos mil dos.

Por eso, a quienes se preguntan con razón, en qué se emplean los impuestos que pago cada año yo les diría: ¿Con qué eficacia se emplean?

Además del pronombre 'yo', la realización de esta primera voz en el discurso se manifiesta a través de los siguientes marcadores identificados en el discurso: 
CUADRO 1. Marcadores para la primera persona singular

\begin{tabular}{|c|c|c|c|c|c|c|c|}
\hline yo & '-o' & '-e' & '-oy' & 'he' & $\mathbf{m i}$ & me & Total \\
\hline 5 & 6 & 7 & 4 & 4 & 22 & 9 & 57 \\
\hline \multirow[t]{2}{*}{$\overline{m i}$} & Voz 1: & \multicolumn{6}{|c|}{ Ustedes conocen mi pensamiento al respecto. } \\
\hline & Voz 2: & \multicolumn{6}{|c|}{$\begin{array}{l}\text { Nuestro producto nacional es cerca de un diez por ciento más alto que el que teniamos al } \\
\text { comenzar mi Gobierno. }\end{array}$} \\
\hline$m e$ & Voz 1: & \multicolumn{6}{|c|}{$\begin{array}{l}\text { La semana pasada me reuni con treinta y dos de estas empresas, que desde Chile prestan } \\
\text { servicios al mundo. }\end{array}$} \\
\hline$-e$ & Voz 1: & \multicolumn{6}{|c|}{ ¿Para eso luché! } \\
\hline-0 & Voz 1: & \multicolumn{6}{|c|}{$\begin{array}{l}\text { Quiero invitar al Parlamento de Chile a que me acompañe para hacer realidad lo que quiere } \\
\text { todo Chile: discutir democraticamente nuestra Constitucion. }\end{array}$} \\
\hline
\end{tabular}

Es interesante señalar que entre los marcadores que expresan la $V o z 1$, el adjetivo posesivo ' $m i$ ' presenta una doble marcación ( $V o z$ y 12 ), que en el $59 \%$ de los casos ocurre como parte del sintagma nominal ' $m i$ gobierno'. En estos casos corresponde a uno de los marcadores de la $\mathrm{Voz} 2$ del enunciador: el Presidente como parte de un gobierno. A través de la Voz 2 , el enunciador se identifica con el colectivo o grupo de personas que gobiernan la nación. ${ }^{6}$ En esta segunda voz tanto el Gobierno como el Presidente de la República -incluida la Oposición como parte del Poder Legislativo- se instauran como un colectivo que se compromete a hacer avanzar a la nación chilena hacia el camino del bien común.

\subsection{MARCADORES FORMALES DEL GRUPO 'NOSOTROS'}

Los marcadores que señalan esta voz, se identifican con los que denominamos el 'grupo nosotros'. Nos referimos principalmente a la desinencia mos' y al pronombre 'nos'. En el discurso presidencial que analizamos, el enunciador emplea estos marcadores mayoritariamente para informar a la nación acerca de los logros y los futuros proyectos de su gobierno, principalmente. Ello le permite, por una parte, identificarse con un grupo de personas que juntas velan por el bien común de Chile y, por otra, dejar de manifiesto un objetivo: la autoconstrucción lingüística de una imagen unificadora: el enunciador que da cuenta a la nación como 'el Presidente de todos los chilenos'.

Si bien la observación de la frecuencia de ocurrencias del uso de la desinencia verbal '-mos' para la $V o z 2$ y 3 no arroja diferencias significativas, la cuantificación de los datos revela que se constituye en el marcador de mayor frecuencia de ocurrencia en nuestro corpus. De hecho, esta desinencia materializa la $\operatorname{Voz} 2$ en un $50.7 \%$ del total de ocurrencias -el Presidente como parte de un gobierno-y la Voz 3 en un $47.6 \%$ de ellas: el Presidente como parte de la nación.

Es interesante advertir que, contrario a lo esperado, se identifican sólo dos casos en los que el Presidente de la República recurre a esta desinencia desde la $V o z$ 1. Las ocurrencias de '-mos' en este caso se 
enmarcan en su calidad de Jefe de Estado (1.58\%). En ambos casos, la Voz 1 ocurre en el contexto del verbo 'señalar', el que remite anafóricamente a información anunciada con anterioridad en el discurso, lo que le facilita la coherencia en la progresión del tópico:

- Están en trámite el proyecto que crea el Tribunal de Defensa de la Competencia, la Ley Eléctrica y, como ya lo señalamos, se aprobó, prácticamente, la Ley de Compras Públicas.

- Vamos a ser capaces, como señalamos, de construir cuarenta nuevos kilómetros de la red de Metro;...

La frecuencia de ocurrencia de los marcadores identificados para el grupo 'nosotros' para las Voces 2 y 3 se aprecia en el siguiente recuadro, en el que observa que a diferencia de la desinencia '-mos', los demás marcadores no materializan la Voz 1 . Nótese que, según se observa en el recuadro, otro marcador de alta frecuencia además de la desinencia 'mos', es el pronombre 'nos'.

CUADRO 2. Marcadores para la primera persona plural

\begin{tabular}{|c|c|c|c|c|c|c|c|c|c|}
\hline nosotros & & & nos & & -nos' & \multicolumn{3}{|c|}{ '-mos' } & Total \\
\hline \multicolumn{2}{|c|}{7} & \multicolumn{2}{|r|}{26} & \multicolumn{2}{|r|}{6} & \multicolumn{3}{|c|}{245} & 284 \\
\hline $\begin{array}{c}\text { V2 } \\
42 \%\end{array}$ & \begin{tabular}{|l|} 
V3 \\
$58 \%$
\end{tabular} & \begin{tabular}{|l|} 
V2 \\
$57 \%$
\end{tabular} & \begin{tabular}{|l|} 
V3 \\
$43 \%$
\end{tabular} & $\begin{array}{l}\mathrm{V} 2 \\
50 \%\end{array}$ & \begin{tabular}{|l|}
$\mathrm{V3}$ \\
$50 \%$
\end{tabular} & $\begin{array}{l}\mathrm{V} 1 \\
1.58 \%\end{array}$ & $\begin{array}{l}\mathrm{V} 2 \\
47.6 \%\end{array}$ & \begin{tabular}{|l|}
$\mathrm{V} 3$ \\
$50.7 \%$
\end{tabular} & \\
\hline
\end{tabular}

El hecho de que no existan diferencias significativas entre el porcentaje de ocurrencias de cada marcador y el tipo de voz empleada por el enunciador, se puede interpretar como la voluntad del Presidente de identificarse con un colectivo, ya sea el grupo de personas que encabeza la dirección del país o bien el país mismo, a la vez que la voluntad de identificar los logros de su gestión con los logros de Chile.

El gráfico siguiente presenta la distribución de la desinencia '- mos' para las voces 1, 2 y 3 y el Cuadro 2, el empleo de los marcadores de mayor frecuencia para el grupo 'nosotros'.

GRÁFICO 1. Distribución desinencia '-mos' V1, V2 y'V3

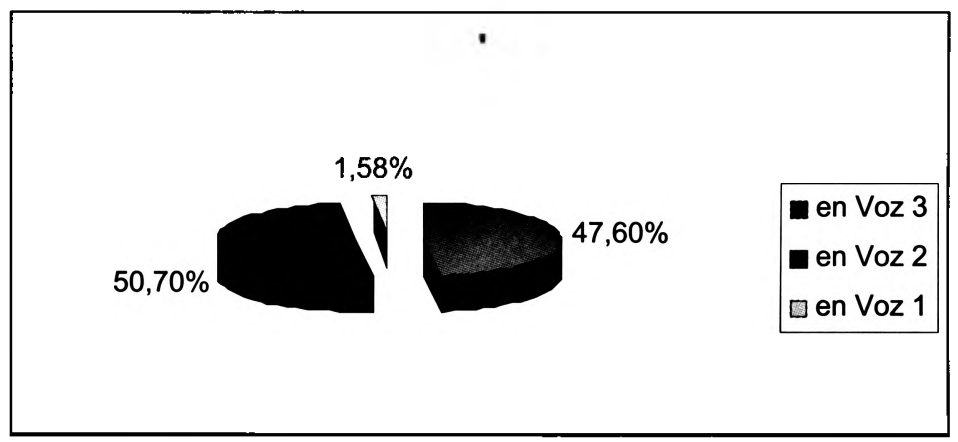


CUADRO 3. Marcadores de mayor frecuencia para el grupo 'nosotros'

\begin{tabular}{|c|c|l|}
\hline $\begin{array}{c}\text {-mos } \\
\text { (245) }\end{array}$ & Voz 1: & $\begin{array}{l}\text { Están en trámite el proyecto que crea el Tribunal de Defensa de la Competencia, la Ley } \\
\text { Eléctrica y, como ya lo señalamos, se aprobo, prácticamente, la Ley de Compras Públicas. }\end{array}$ \\
\cline { 2 - 3 } & Voz 2: & $\begin{array}{l}\text { Esto es lo que hemos estado haciendo con éxito en este Congreso } \\
\text { Nacional de manera unida basta ayer mismo en la tarde. }\end{array}$ \\
\cline { 2 - 3 } & Voz 3: $: \begin{array}{l}\text { Ese no es el Chile que heredamos de nuestros antepasados, ni el Chile que queremos dejar } \\
\text { como legado a nuestros hijos. }\end{array}$ \\
\hline $\begin{array}{l}\text { Nos } \\
(26)\end{array}$ & Voz 2: & $\begin{array}{l}\text { Nos propusimos que cada ciudad de más de diez mil habitantes estuviera } \\
\text { conectada al resto de Chile por un camino pavimentado. }\end{array}$ \\
\cline { 2 - 4 } & Voz 3: & $\begin{array}{l}\text { Pero también es imprescindible cuidar la dignidad de las personas, elevar la } \\
\text { calidad del debate, cuidar el equilibrio y la justicia en el trato que nos damos } \\
\text { todos los chilenos. }\end{array}$ \\
\hline
\end{tabular}

La suma de los marcadores formales para cada una de las voces muestra la tendencia del enunciador a construir una imagen que se proyecta mayoritariamente como parte de un colectivo; en otras palabras, parte del grupo de personas de cuya gestión depende el futuro de la nación, o bien parte de un colectivo mayor que implica a Chile en su conjunto, en el que el enunciador evalúa la gestión y los logros del Gobierno como un ciudadano más de la nación.

\subsection{CORRELACIÓN ENTRE LAS VOCES DEL ENUNCIADOR Y LOS ACTOS DE HABLA}

La correlación entre las tres voces del enunciador y los actos de habla en los que ocurren los marcadores formales que materializan estas voces nos permite identificar con mayor objetividad y precisión la intencionalidad del enunciador en el discurso presidencial que analizamos.

\subsubsection{PARA LA VOZ 1}

En sus 22 ocurrencias, el adjetivo posesivo ' $m i$ ' ocurre mayoritariamente en actos de habla asertivos-informativos (36\%), con frecuencia menor en actos asertivos-confirmativos (18\%), en asertivos-aseverativos y compromisivos (13\%), lo que indica que al seleccionar este marcador de Voz 1, el enunciador informa, comunica, confirma, afirma, sostiene y se compromete personalmente como Presidente de la República:

- Di mi opinión el año pasado sobre el peculiar sistema que tenemos y los riesgos que conlleva que, después de una intensa lucha electoral, tengamos un Parlamento empatado, cualesquiera que sea su resultado. (asertivo-informativo /comunicar)

GRÁFICO 2. Correlación entre las voces del enunciador y los actos de habla Voz 1: desinencia ' $m i$ ' 
Por su parte, el pronombre ' $m e$ ' ( 9 ocurrencias), se adscribe principalmente a actos de tipo asertivo-informativo (44\%) y en actos asertivosaseverativos (33\%). Lo mismo ocurre con la desinencia '- $e$ ', la que en el $50 \%$ de las ocurrencias se manifiesta en estos mismos tipos de actos. A través de la materialización de estos marcadores de $V o z l$ en estos tipos de actos, el enunciador manifiesta su propia opinión como Jefe de Estado sobre los temas que atañen a Chile:

- Sin embargo, me gustaría que el debate sobre nuestro sistema electoral sea, aparte de la Carta Fundamental, para asegurar en el futuro próximo un procedimiento que permita el efectivo predominio de mayorias y asegure el respeto de los derechos de la minoria, esencia del sistema democrático. (asertivo-aseverativo/opinar)

- Hace justo un año, en este mismo Congreso Nacional, señalé que estamos trabajando para construir un Chile más productivo, más confiable y más humano. (asertivo-informativo/comunicar)

GRÁFICO 3. Correlación entre voces del enunciador y actos de habla Voz 1: marcadores 'me' $y$ '-e'
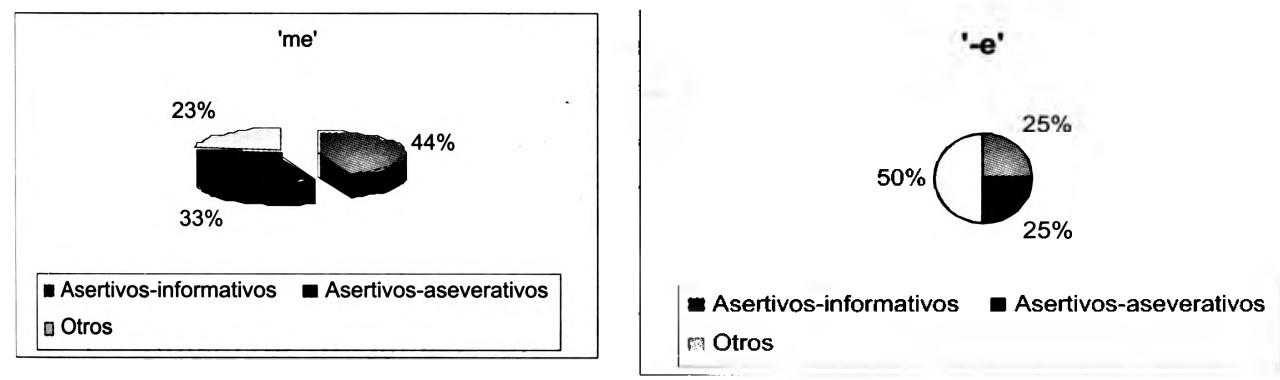

El bajo porcentaje de ocurrencias de los demás marcadores de Voz 1 no permite apreciar una correlación significativa con cada uno de los tipos de actos de habla identificados. Sin embargo, en el contexto de la totalidad de los marcadores estudiados, podemos deducir que la mayoría de estos ocurren en actos principalmente asertivos (46\%), informativos $(26 \%)$ y aseverativos $(17 \%)$.

\section{3. 2 Para las VOCES 2 Y3}

A) Desinencia '-Mos'

Nuestro estudio revela que, en general, los marcadores que materializan las Voces 2 y 3 se concentran mayoritariamente en actos de habla asertivos-aseverativos (36.5\%) seguidos de actos asertivos-informativos $(23.8 \%)$ y otros $(39.7 \%)$. El marcador que ocurre con mayor frecuencia en estos tipos de actos es la desinencia '-mos'. 
GRÁFICO 4. Correlación entre voces del enunciador y actos de habla Voces 2 y 3: desinencia '-mos'

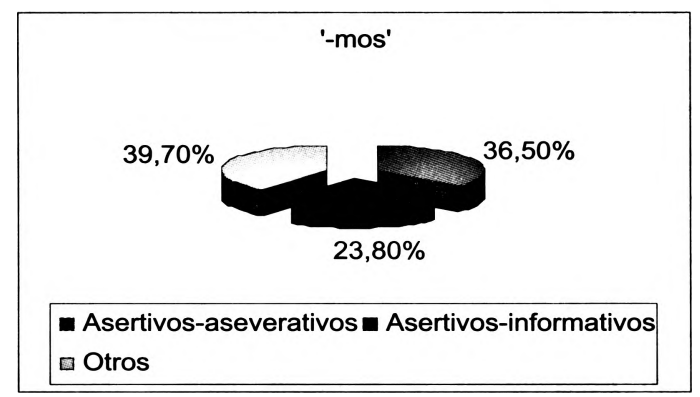

Los otros marcadores se distribuyen de manera irregular en los demás tipos de actos. La articulación que existe entre estos tipos de actos y los tipos de voces materializadas en la desinencia '-mos', revela que el Presidente desea que sus destinatarios (los chilenos) se identifiquen con aquello que él informa o asevera; en general, el éxito que él, como parte de su gobierno, ha logrado para Chile. Este hallazgo parece concordante con lo expresado hacia el término de su discurso:

- Chile tiene que ser no sólo un territorio, sino su espiritu. Y ese espiritu, tal como lo hacemos con la llama que calienta nuestra morada o que señala el camino, tiene que ser avivado a cada instante por el esmero que ponemos en las cosas importantes. Chile tiene que ser no sólo nuestro pais, tiene que ser nuestro orgullo.(Asertivo-aseverativo/V2)

B) Pronombre 'Nos'

El pronombre 'nos', refleja en un $57.7 \%$ de ocurrencias la $V o z 2$ y en un $42.3 \%$ la presencia de la $V o z$ 3. Este fenómeno se manifiesta mayoritariamente en actos de habla de tipo aserrivo-aseverativo y asertivo-informativo, lo que revela el propósito del Presidente en su discurso presidencial: sostener con convicción aquello que Chile debe alcanzar e informar sobre los logros de su gobierno.

GRÁFICO 5. Correlación entre voces del enunciador y actos de habla: Pronombre 'nos'

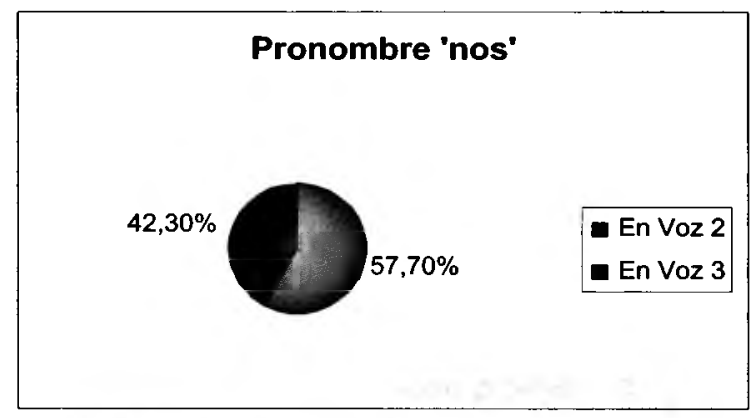


- Y junto a esto nos propusimos hacer un Chile más bumano. Mejorar las condiciones de vida. Comenzar por mejorar las condiciones de vida es lo más esencial: su vivienda. Nos propusimos aumentar drásticamente el gasto en vivienda dirigido a los sectores más pobres. (asertivo-informativo/informar/V2)

- Entendámoslo bien: la adaptabilidad laboral acordada entre empresarios y trabajadores, con la participación activa de los sindicatos, nos va a permitir tener empresas más productivas, nuevas fuentes de trabajo, mejor calidad de vida para los trabajadores, nuevos roles para los sindicatos. En último término, progreso para Chile. (asertivo-aseverativo/afirmar/V 3)

C) DESINENCIA '-NOS' Y PRONOMBRE 'NOSOTROS'

Por su parte, tanto la desinencia '-nos' como el pronombre 'nosotros' presentan escasa ocurrencia (6 y 7 , respectivamente). Se concentran, mayoritariamente, en actos asertivos-aseverativos y asertivos-informativos, sin diferencias significativas en el empleo de las Voces 2 y 3:

- Si queremos mantenernos en la posición que tenemos en el mundo de hoy, tenemos que mantener los procesos de modernización de una manera permanente. (asertivo-aseverativo/afirmar/V2)

- Yo me comprometí, como candidato, a que el debate sobre el número y cuáles serán las regiones debe hacerse entre todos nosotros. (asertivo-informativo/ recordar /V2)

Cabe destacar que si bien es cierto que la mayoría de los marcadores se concentran en actos de tipo asertivo, existe un número no menor de marcadores de primera persona plural (13) que ocurren en actos directivos-requeridores. Se trata de las desinencias '-mos' y '-nos'y el pronombre 'nosotros'. Esta evidencia revela que el género discurso presidencial no es sólo una instancia para informar, anunciar o sostener sino que en él, el enunciador también busca un espacio para solicitar a las distintas esferas políticas e institucionales del quehacer nacional aquello que se ajusta a su ideal de país. Más aún, es relevante señalar que en este tipo de actos la voz predominante es la Voz 3. Pareciera, entonces, que es el Presidente en su calidad de chileno quien se dirige a Chile, sin romper del todo la asimetría entre enunciador y destinatario propia de este evento comunicativo; vale decir, se instaura en el colectivo y desde de él requiere, pide, insiste y solicita.

- Cuidemos a Chile. Tratemos con cariño esta patria que es la patria de todos. (directivo-requeridor/ requerir/V3)

\subsection{RECURSOS DE FOCALIZACIÓN}

Así como los deícticos 'yo' y 'nosotros', los pronombres 'me', 'nos', las desinencias verbales y la fuerza ilocutiva de los actos de habla, los recursos de focalización también constituyen un recurso que ayuda a configurar la caracterización de las voces del enunciador. Si bien la coocurrencia de 
estos recursos no es de alta frecuencia, constituyen un factor de apoyo retórico a la construcción de estas. Entre los recursos de focalización que coocurren con los marcadores anteriormente mencionados, destacamos los recursos sintácticos de orden, deícticos temporales y espaciales, demostrativos en aseveraciones rotundas, estructuras ecuacionales, estructura 'lo que es' y reduplicación.

\subsubsection{RECURSOS SINTÁCTICOS}

ORDEN

Al instaurarse el enunciador en las Voces 1 y 3 , en actos de habla asertivos-aseverativos o disentivos principalmente, recurre con fines de énfasis a la alteración del orden sintáctico de los segmentos que desempeñan la función 'sujeto', quedando este focalizado en posición final:

[Frente a la guerra de Irak hubo quienes pensaron que lo mejor era el silencio, la ausencia de opinión o apegarse a una visión puramente mezquina y utilitaria de los intereses de Chile.] No es esa mi idea de Chile. (Asertivo-disentivo / V1)

DefCTICOS TEMPORALES Y ESPACIALES: 'HOY', 'AQUI'

En las Voces 2 y 3 en actos de habla asertivos-informativos y también en algunos asertivos-aseverativos y directivos-requeridores, el enunciador recurre al empleo de los deícticos 'hoy', 'aqui' en posición de información temática, los que desplazados a la izquierda, desempeñan una función presentativa y se convierten en apoyo enfático:

- Aqui estamos generando un espacio para nuestros jóvenes, para nuestros adultos, para entender que la calidad de vida son muchos elementos... (asertivo-aseverativo) $\mathrm{V} 2$

- Hoy todos debemos estar orgullosos de un país que tiene solo - con un cuatro por ciento de analfabetismo, porcentaje inferior al de varios paises del sur $y$ centro de Europa. .. (directivo-requeridor) V3

\section{DEMOSTRATIVOS EN ASEVERACIONES ROTUNDAS}

En las Voces 2 o 3, recurre también con cierta frecuencia, al uso de los demostrativos 'este', 'ese' y 'eso', para introducir actos de habla focalizados como resultado de inversión en el orden sintáctico. Estos corresponden a aseveraciones rotundas para entregar ya sea información nueva o para enfatizar un planteamiento con una carga prosódica más propia de actos netamente expresivos.

- [La gran mayoria de quienes trabajan tanto en el ámbito público como privado son gente honesta, de esfuerzo, de sólidos valores éticos y humanistas.] Este es el soporte moral de la convivencia, de nuestra convivencia. (asertivoaseverativo/V3) 


\subsubsection{ESTUCTURAS SINTÁCTICAS ESPECIALES: ESTRUCTURAS ECUACIONALES Y ESTRUCTURA ENFÁTICA 'LO QUE ES'}

En estos casos, el enunciador en $V o z 3$ opta con frecuencia por el esquema $\mathrm{A}$ es $\mathrm{B}$ en actos de habla asertivos-aseverativos para sostener con firmeza su planteamiento:

- Ese es el Chile que queremos expandir: una nación que camina con paso seguro hacia el desarrollo, con la mirada puesta en el bicentenario. (asertivoaseverativo/V3)

- Ese es el Chile que queremos. (asertivo-aseverativo/V3)

\section{ESTRUCTURA ENFATICA 'LO QUE ES'}

Aunque en escasas ocasiones, el enunciador recurre en $\mathrm{Voz} 3$, al empleo de esta estructura para anunciar con precisión un proyecto en actos asertivos-aseverativos.

- Y próximamente anunciaremos el Plan de Desarrollo Ganadero, que nos permitirá aprovechar aún más lo que son las ventajas de los acuerdos internacionales recientemente logrados. (asertivo-aseverativo/ V 3)

\subsubsection{REDUPLICACIÓN CON EXPANSIÓN}

Con escasa frecuencia el enunciador recurre en $\operatorname{Voz} 2$, a la repetición de un elemento o de un segmento del enunciado como una forma de insistencia para expandir el planteamiento en la segunda repetición en actos asertivos-aseverativos:

- Fue un testimonio duro, fuerte, que nos emocionó. Nos emocionó no porque dio las gracias, nos emocionó porque pensó que tenía una posibilidad de surgir a partir de una sociedad que le tendió la mano en Chile Solidario. (asertivoaseverativo/ V2)

\section{Conclusiones}

En cuanto a los marcadores y las voces enunciativas, podemos concluir que los exponentes de las voces que asume el enunciador en este discurso corresponden a los deícticos 'yo', en representación del Presidente como Jefe de Estado y 'nosotros', el que incorpora al enunciador a un grupo, ya sea el Presidente como parte de un gobierno o el Presidente como parte de la nación. El grupo le proporciona la responsabilidad de lo enunciado y lo incorpora como parte de un colectivo (gobierno, país). Al recurrir al 'nosotros', el enunciador puede, por tanto, inscribirse de diferentes maneras en el discurso dependiendo del grado de imposición, responsabilidad asumida o diluida con el destinatario o de compromiso con lo que dice. 
Cabe destacar, sin embargo, que estos deícticos no constituyen los únicos marcadores de autorreferencia ni son los de mayor frecuencia en nuestro corpus. Tanto las desinencias verbales del 'yo' o del 'nosotros' como el empleo de sintagmas nominales, como por ejemplo, 'mi gobierno', pueden adquirir igual fuerza en la marcación de las voces del enunciador. Podemos concluir que, en general, el análisis de este discurso presidencial revela el empleo de marcadores que construyen voces mayoritariamente colectivas que consolidan al líder de gobierno como parte de un conglomerado amplio, dejando los marcadores de primera persona para vislumbrar la persona tras el mandatario.

En cuanto a las voces del enunciador y los actos de habla, al emplear la $V o z$ 1, encabezan la lista de preferencias del Presidente de la República lo: actos informativos, aseverativos y compromisivos, en orden de mayor a menor frecuencia. De ello se desprende que el enunciador favorece el usc de actos en los que, en su papel como Jefe de Estado, afirma sus creencias sobre el tipo de gestión de la que da cuenta en concordancia con el concepto-país que él cree debe encarnar. En esta práctica discursiva encuentra la instancia para comprometerse como Jefe de Estado ante là nación en relación con determinadas tareas.

Por su parte, al emplear las Voces 2 y 3, encabezan la lista de preferencias del Presidente de la República, en orden de mayor a menor frecuencia, los actos informativos, aseverativos y requeridores. En efecto, el enunciador favorece el uso de actos en los que informa a la nación sobre los logros que él como líder del gobierno, y desde el gobierno, ha alcanzado para Chile. La estrategia de identificación con el colectivo nacional en esta instancia discursiva puede reducirse a la fórmula: logros del gobierno = logros de la nación. De ahí que en estas voces encuentre una ocasión para requerir desde Chile y solicitar a Chile. Ello concuerda con la imagen construida y su proyecto como Presidente.

Sobre los recursos de focalización, el análisis realizado revela la coocurrencia de recursos sintácticos de orden, deícticos temporales y espaciales, demostrativos en aseveraciones rotundas, estructuras ecuacionales, estructura enfática 'lo que es' y reduplicación en ciertos actos de habla junto a los deícticos, pronombres y desinencias verbales como recursos de apoyo retórico en la construcción de las voces 1,2 y 3. La coocurrencia de estos recursos permite al Presidente sostener con mayor fuerza sus planteamientos, requeriro disentir cuando lo estima conveniente.

Por último, en relación con los destinatarios, que si bien la audiencia del discurso en estudio corresponde a una audiencia presencial y virtual, con destinatarios que pueden o no coincidir con el perfil político del enunciador, estos destinatarios, por su capacidad de respuesta, condicionan la selección lingüística, las funciones informativas empleadas y la fuerza ilocutiva que el enunciador imprime a su discurso. 


\section{NOTAS}

1 Este artículo es el resultado de una ponencia presentada en el XVI Congreso de la SOCHIL Universidad Austral de Valdivia, Chile, del 2 al 5 de noviembre del 2005.

2 Ricardo Lagos Escobar es el tercer Presidente de la Concertación por la Democracia, conglomerado de partidos políticos de tendencia de centro izquierda que gobierna desde la vuelta a la democracia en Chile en el año 1990.

3 Proyecto coordinado por Miriam Cid U., (2002-2005), titulado "Patrones prosódicos recurrentes en los actos de habla pública de Chile: descripción fonofonológica".

4 La noción de actos de habla que urilizamos se basa en el modelo postulado por Searle (1969), cuya taxonomía hemos complementado con la subcategorización propuesta por Moreno Cabrera (1994).

5 En cuanto a las funciones informativas o pragmáticas, éstas corresponden a las clásicas que reconoce la literatura de la especialidad (Gutiérrez, 1997; Bosque y Demonte, 1999). En este trabajo hacemos referencia a algunos procedimientos de focalización como elementos que colaboran en la construcción de la voz del enunciador.

6 El concepto de gobierno que empleamos para definir esta voz corresponde a un concepto de gobierno en un sentido amplio, vale decir, incluye al Presidente, sus ministros, intendentes, gobernadores, jefes de servicios e incluso en ocasiones al Congreso nacional.

\section{REFERENCIAS BIBLIOGRÁFICAS}

AUSTIN, J.L. (1962) How to do things with words. Oxford: Oxford University Press. BERARDI, L. (ed) (2003) Análisis critico del discurso. Perspectivas latinoamericanas. Santiago: Frasis editores.

BOSQUE, I. y DEMONTE, V. (eds.) (1999) Gramática descriptiva de la lengua española.

Madrid: Espasa-Calpe.

BRUNNER, J.J.(1983) Entrevistas, discursos, identidades. Santiago de Chile: Facultad Latinoamericana de Ciencias Sociales.

BURDACH, A. M. \& POBLETE, M. (2005) 'El fenómeno de focalización en el habla pública de Chile', Onomázein 11, 23-42.

BURDACH, A. M. \& J.L. SAMANIEGO (2005) La fuerza ilocutiva y la organización de la información en el discurso presidencial de Ricardo Lagos. Ponencia presentada en el VI Coloquio Latinoamericano de Estudios del Discurso y III Congreso Latinoamericano de Estudios del Discurso. Santiago, PUC, Chile, del 5 al 9 de septiembre de 2005.

CALSAMIGLIA BLANCAFORT, H. \& TUSÓN VALLS, A. (1999) Las cosas del decir. Manual de análisis del discurso. Barcelona: Ariel.

CID, M., ROSS, P. \& J. L. SAMANIEGO (2004) 'Habla pública: hacia un nuevo concepto', Onomázein, 10: 179-184.

CHARAUDEAU, P. (2001) 'De la competencia social de comunicación a las competencias discursivas', Revista Latinoamericana de Estudios del Discurso Vol 1(1): 7-22.

DUCROT, O. (1984 [1986]) El decir y lo dicho. Polifonia de la enunciación. Barcelona: Paidós.

GOFFMAN, E. (1959 [1987]) La presentación de la persona en la vida cotidiana. Madrid: Amorrortu-Murguía. 
GOFFMAN, E. (1967 [1970]) Ritual de la interacción. Ensayos sobre el comportamiento cara a cara. Buenos Aires: Tiempo Contemporáneo.

GOFFMAN, E. (1971 [1979]) Relaciones en público. Madrid: Alianza.

GOFFMAN, E. (1981) Forms of Talk. Filadelfia: University of Pennsylvania Press.

GUTIÉRREZ ORDONEZZ, S. (1997) Temas, remas, focos, topicos y comentarios. Madrid: Arco Libros.

MOLERO DE CABEZA, L. (2002) 'El personalismo en el discurso político venezolano. Un enfoque semántico y pragmático', en línea http:// convergencia.uaemex.mx/re29/29pdf/lourdesmolero04.pdf

MORENO CABRERA, J.C. (1994) Curso universitario de lingüistica general: semántica, pragmática, morfología y fonologia. Vol 2. Madrid: Editorial Síntesis.

POBLETE, M., PONS, H. y J. L. SAMANIEGO A. (2000) 'Fenómenos gramaticales y recursos modalizadores del enunciado en el español culto de Santiago de Chile', Onomázein, 5: 143-151.

SEARLE, J. (1969) Speech Acts. Cambridge: Cambridge University Press.

VAN DIJK, T. (1995) 'De la gramática del texto al análisis crítico del discurso', Boletín de Estudios Lingüisticos Argentino, 2(6), 20-40.

ANA MARÍA BURDACH es profesora de inglés. Obtuvo el grado de Magíster en Lingüística Inglesa y es Doctora en Linguiística y Filología Hispánica. Ha trabajado en investigación en el ámbito del análisis del discurso, en particular, en patrones que configuran el discurso publicitario y político, tanto en lengua materna como en la lengua inglesa, y en la descripción de patrones prosódicos recurrentes en actos de habla pública de Chile. Realiza docencia de pregrado y postgrado y dirige tesis de Magíster sobre implicaturas pragmáticas en el texto publicitario, la evaluación en el discurso político, las funciones de las secuencias narrativas en los cuentos infantiles y la subjetividad en los textos periodísticos.

Correo electrónico: aburdach@uc.cl

PAULA ROSS A. es licenciada en educación y profesora de inglés de la Pontificia Universidad Católica de Chile; obtuvo el grado de Magíster en Letras con mención en Lingüística Aplicada, en la misma universidad. Actualmente se desempeńa como académica en dicha universidad realizando docencia de pregrado y posgrado para el Programa de Letras Inglesas. Sus investigaciones y publicaciones recientes se originan de su participación en el proyecto de investigación FONDECYT que estudió el habla pública de Chile.

Correo electrónico: aburdach@uc.cl 